\title{
Metallographic Determination of Strain Distribution in Cold Extruded Aluminum Gear-Like Element
}

\author{
Plavka Skakun ${ }^{1}$, Dragan Rajnovic ${ }^{1, *} \mathbb{C D}^{\text {, Petar Janjatovic }}{ }^{1}$ (), Sebastian Balos ${ }^{1}$, \\ Andrei Shishkin ${ }^{2}$ D, Pavel Novak ${ }^{3}$ and Leposava Sidjanin ${ }^{1}$ \\ 1 Department for Production Engineering, Faculty of Technical Science, University of Novi Sad, Novi Sad, \\ Serbia, Trg Dositeja Obradovica 6, 21000 Novi Sad, Serbia; plavkas@uns.ac.rs (P.S.); \\ janjatovic@uns.ac.rs (P.J.); sebab@uns.ac.rs (S.B.); lepas@uns.ac.rs (L.S.) \\ 2 Rudolfs Cimdins Riga Biomaterials Innovations and Development Centre of RTU, Institute of General \\ Chemical Engineering, Faculty of Materials Science and Applied Chemistry, Riga Technical University, \\ Pulka street 3, LV-1007 Riga, Latvia; andrejs.siskins@rtu.lv \\ 3 Department of Metals and Corrosion Engineering, University of Chemistry and Technology, Prague, \\ Technicka 5, 16628 Prague 6, Czech Republic; Paja.Novak@vscht.cz \\ * Correspondence: draganr@uns.ac.rs; Tel.: +381-21-485-2338
}

Received: 13 April 2020; Accepted: 28 April 2020; Published: 30 April 2020

\begin{abstract}
In this study, an experimental, metallographic method for determining strain distribution in a cold extruded aluminum gear-like element, based on the dependence of recrystallized grain size on prior deformation, was devised in order to overcome design problems in manufacturing of complex parts where critical values of strain and stress could cause a fracture. The method was applied on a 99.5\% aluminum bar subjected to cold, radial extrusion, in order to produce complex gear-like element. To reveal the strain and stress distribution in specimens, the calibration and flow curves were first obtained by uniaxial compression (Rastegaev test). Afterwards, the grain size in different parts of the gear section was examined, the strain and stress distributions were calculated, and the results were confirmed by microhardness measurements. It was found that grain size, strain, stress, and microhardness considerably differed throughout the cross-section of the gear. The coarsest grain, and thus the lowest strain zone, was obtained in the central part of the tooth and in the zone between teeth. Conversely, the finest grains appeared in the highest strain zone at the specimen surface, particularly in the root of the teeth. Furthermore, results were supported by microhardness measurements, i.e., microhardness corresponded to grain size and strain hardening. Finally, the real view of material flow in the complex extruded part was successfully obtained by the metallographic method.
\end{abstract}

Keywords: metallographic method; grain size; deformation; strain; stress; extrusion; aluminum

\section{Introduction}

Cold extrusion of gear-like elements is a forming process which has many advantages compared to other manufacturing processes, such as machining or casting. Parts obtained in this process have higher mechanical properties, due to strain hardening, than those made by machining or casting, while, production time could be shorter, and less material is lost compared to machining [1]. Application of this process is limited, due to the high values of required forming load, which affects the size of the parts that can be produced, as well as part accuracy and tooling life. For these reasons, the information about process parameters like forming load, punch pressure, and stress and strain distributions within the part volume are of great interest when it comes to process design [1,2]. Expected values of forming load and punch pressure help define the number of process stages, as well as the design of the tool, while values of stress and strain could indicate the location of potential critical fracture zones within the workpiece [1]. 
The forming loads in the extrusion and the forging processes are often predicted by numerical simulation [1-3], or by theoretical analysis, such as the upper bound method [4-6]. The obtained results about the forming load were verified straightforwardly by experiment [5,6]. When it comes to the determination of stress and strain state, numerical analysis and simulations were dominantly applied [7-13]. Unfortunately, the experimental approaches, by microhardness measurement [14], or by grain size measurement $[15,16]$ are not so common. Strain values in critical zones of the workpiece, where deformation is localized, or fracture occurs, can be predicted from workability diagrams [17,18]. It is well known that the final properties and the behavior of the material during deformation are dependent on the microstructure $[19,20]$. However, the aforementioned literature survey revealed that the experimental correlation between strain state and microstructure is very rare.

For those reasons (design problems, and lack of experimental correlation and data), in this paper, an experimental procedure for strain determination within a cold extruded aluminum workpiece based on the microstructure is presented. This procedure was designed on the phenomena of dependence between recrystallized grain size and prior deformation. The method was applied to determine the strain distribution in a cold radial extruded aluminum gear-like element. By utilizing the flow curve and obtained strain distribution, the stress distribution in the extruded specimens will be revealed, also. Consequently, the real view of material flow in the extruded part will be obtained by a metallographic method for determination of strain distribution.

\section{Materials and Methods}

The material used in this study was Al 99.5\% (EN AW1050A), provided in the form of a bar with $30 \mathrm{~mm}$ diameter. The chemical composition of the Al-bar is given in Table 1.

Table 1. Chemical composition of the Al-bar.

\begin{tabular}{cccccccccc}
\hline $\mathbf{C u}$ & $\mathbf{M n}$ & $\mathbf{M g}$ & $\mathbf{S i}$ & $\mathbf{F e}$ & $\mathbf{Z n}$ & $\mathbf{T i}$ & $\mathbf{P b}$ & $\mathbf{S n}$ & $\mathbf{A l}$ \\
\hline 0.02 & 0.003 & 0.016 & 0.13 & 0.28 & 0.05 & 0.018 & 0.006 & 0.005 & balance \\
\hline
\end{tabular}

The specimens for the extrusion, the calibration curve, and flow curve have to undergo the same procedure to achieve the same initial microstructure. According to that, all specimens were first heattreated for $16 \mathrm{~h}$ at $600{ }^{\circ} \mathrm{C}$, followed by air cooling. After an initial heat treatment, the specimens were deformed with an effective strain $\varphi=0.25$, and then again heat-treated at $500{ }^{\circ} \mathrm{C}$ for $1 \mathrm{~h}$. As a result, the uniform grain size and chemical homogenization of material were obtained, resulting in uniform grain size of the average $d=287 \pm 52 \mu \mathrm{m}$ (Figure 1) and microhardness of 27.7 HV0.1 (the experimental procedure used is described subsequently).

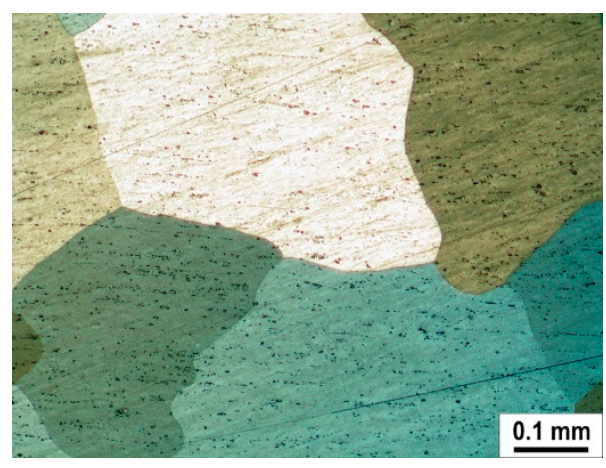

Figure 1. The microstructure of the material used (polarized light microscope).

To obtain the calibration curve and flow curve, the Rastegaev method [21] was carried out. The Rastegaev method produced a uniform distribution of deformation through the specimen. In this process, uniaxial compression was achieved due to friction elimination on the contact surfaces between 
tool and specimens. Upset specimens had a cylindrical shape (no barreling occurred) which indicated that uniaxial stress state was achieved, and that strain distribution was uniform.

The flow curve was determined after specimen deformation with logarithmic strain $\varphi$ between 0.1 and 1.2, at an increment of 0.1 . Three repetitions on different specimens were performed. According to the Rastegaev method, the flow curve was obtained with a final analytical form:

$$
k=152.49 \cdot \varphi^{0.292}(\mathrm{MPa})
$$

where: $k$ is true stress (MPa), and $\varphi$ is the logarithmic strain.

In order to evaluate the strain state within a cold extruded aluminum workpiece, it was necessary to determine the calibration curve which gives a relationship between the recrystallized grain size and the strain. For that purpose, the upsetting by the Rastegaev method was used, also. The logarithmic strain $\varphi$ was between 0.1 and 1.07, in nine steps. Before, metallographic specimen preparation the heat treatment at $500{ }^{\circ} \mathrm{C}$ for $1 \mathrm{~h}$ was used again in order to achieve recrystallization of grains. After that, the metallographic examination and grain size measurement were carried out (the procedure of metallographic preparation and grain size measurement is described later).

The extrusion experiment was performed by special tooling (Figure 2), which was mounted on the hydraulic press model 630T (Sack and Kiesselbach, Germany), with a maximum force of 6.3 MN. The billet was placed into the die and the punch pressed it downwards. In this way, the material was forced to flow into the geared profile of the die insert. The die insert was replaceable, in order to enable extrusion of different gear-like elements. The extruded gear-like element with a replaceable die insert is presented in Figure 3.

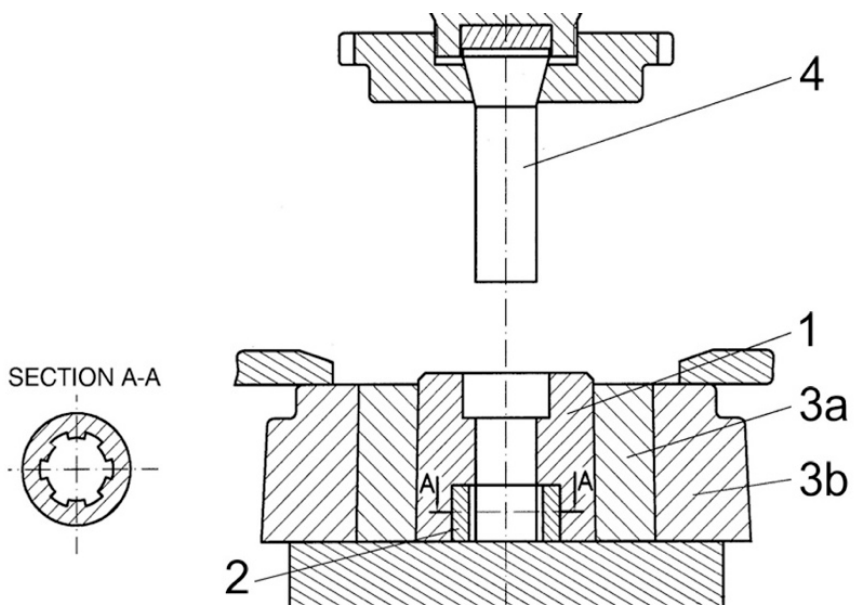

Figure 2. Experimental tooling: 1 die, 2 replaceable die insert, 3a,b inner and outer ring, 4 punch.

The metallographic examinations for all specimens were done after the standard metallographic preparation: (i) grinding with SiC papers (from 220 up to 2500 grid); (ii) polishing with diamond suspension (6, 3, 1 and $\frac{1}{4} \mu \mathrm{m}$ grain size); and finally (iii) polishing with colloidal silica polishing suspension. To develop the $\mathrm{Al}$ grains the anodic oxidation etching in Barkers reagent $\mathrm{HBF}_{4}(5 \mathrm{~mL}$ $\mathrm{HBF}_{4}+200 \mathrm{~mL}$ distilled $\mathrm{H}_{2} \mathrm{O}$ ) was applied. All specimens were examined with an Orthoplan (Leitz, Germany) light microscope under polarized light (polarized LM).

In addition to a qualitative analysis of a microstructure, a quantitative analysis of the apparent grain size according to procedure EN ISO 643:2012 was done. To obtain the apparent grain size, a circular intercept method was used (EN ISO 643:2012) which averages out variations in the shape of equiaxed grains and avoids the problem of lines ending within grains. For the measurement, the three concentric circles were used on the five randomly selected fields of view with appropriate magnification (from 20 to 100 times), in order to achieve at least 40 to 50 intercepts on one field of view. The obtained mean intersected segment $(l)$ was multiplied with 1.106 (the average ratio of the mean diameter of grain and 
mean intersected segment according to standard EN ISO 643:2012) to obtain the mean diameter of grains $(d)$.
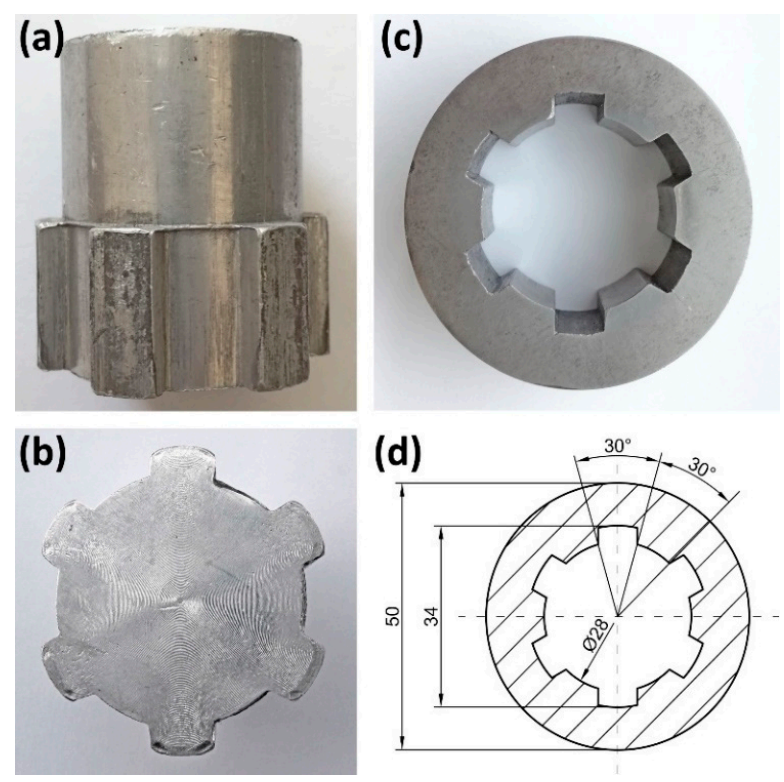

Figure 3. Extruded gear-like element $(\mathbf{a}, \mathbf{b})$ and corresponding die insert (c,d).

The Vickers microhardness measurements were performed according to standard EN ISO 6507-1:2018, on a Wilson Tukon 1102 (Buehler, Lake Bluff, IL, USA) hardness testing device with $0.1 \mathrm{kgf}(0.9807 \mathrm{~N})$ load and $30 \mathrm{~s}$ dwell time. The measurements were done at the outer surface of the extruded gear-like specimen and trough cross-section.

The section of the extruded gear-like element used for microstructure analysis and microhardness measurement is schematically shown in Figure 4. The positions of measurements, later shown on figures, are given in polar coordinates for angles $0-30^{\circ}$, and for radius from the center of element $0-17 \mathrm{~mm}$.

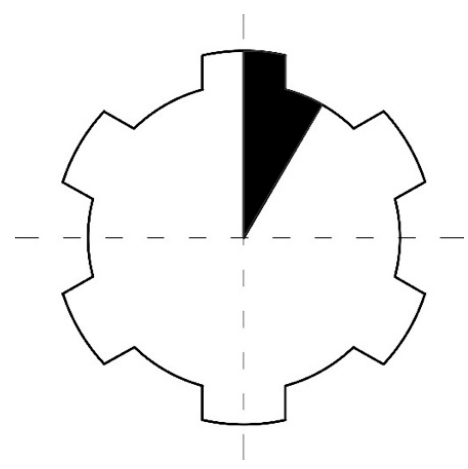

Figure 4. Scheme of the section for microstructure analysis and microhardness measurement.

\section{Results}

\subsection{Calibration Curve}

The calibration curve, mean grain diameter vs. strain, is presented in Figure 5. This is the typical recrystallization diagram, where the grain size of each micrograph (Figure 6) with a linear intercept is correlated to the strain. The curve is approximated by the power function with a coefficient of determination $\mathrm{R}^{2}=0.974$ :

$$
\varphi=44.357 \cdot d^{-0.973},
$$

where: $\varphi$ is the logarithmic strain, and $d$ is grain diameter $(\mu \mathrm{m})$. 


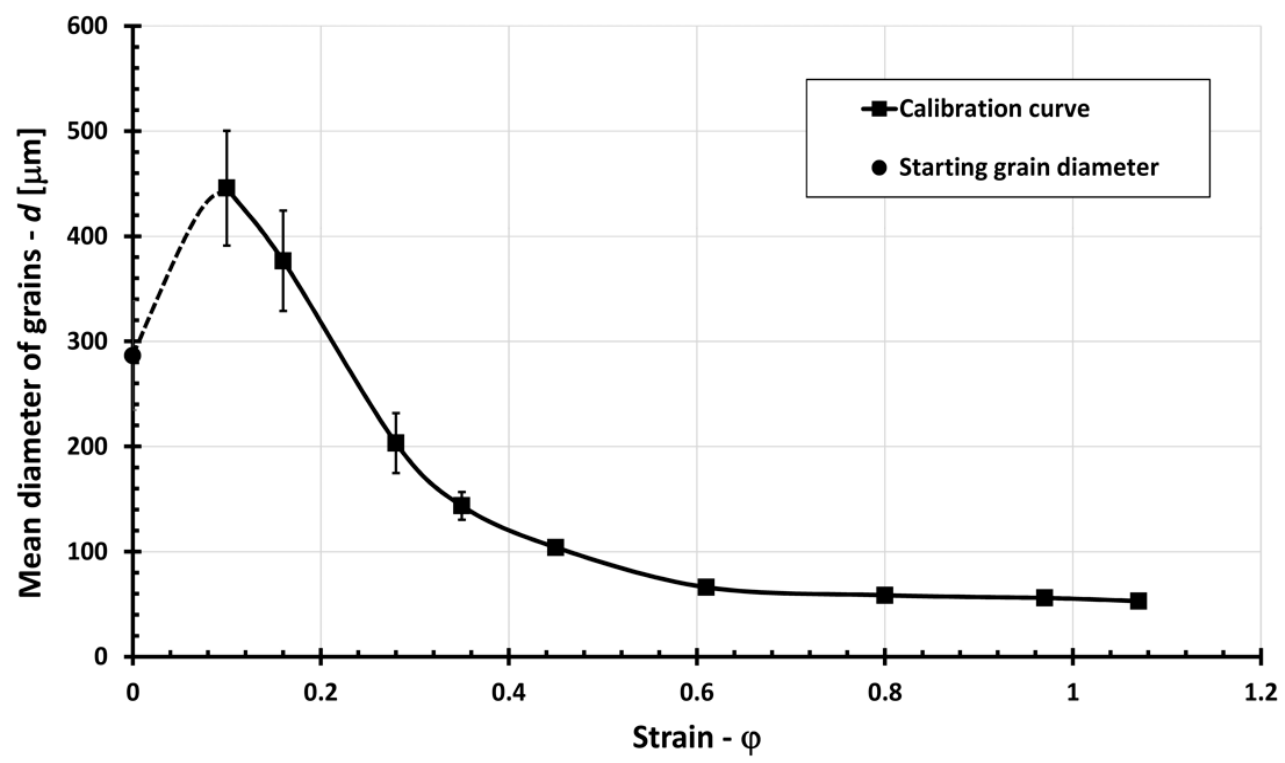

Figure 5. Calibration curve: mean grain diameter vs. strain.

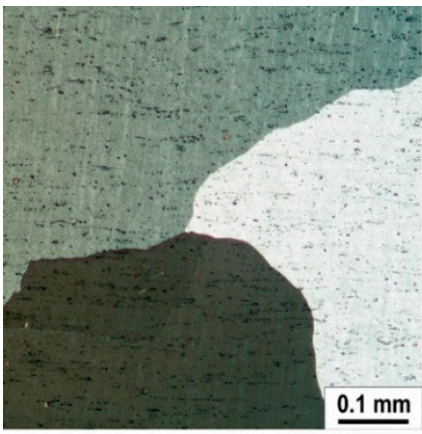

$\varphi=0.1 ; d=445.6 \mu \mathrm{m}$

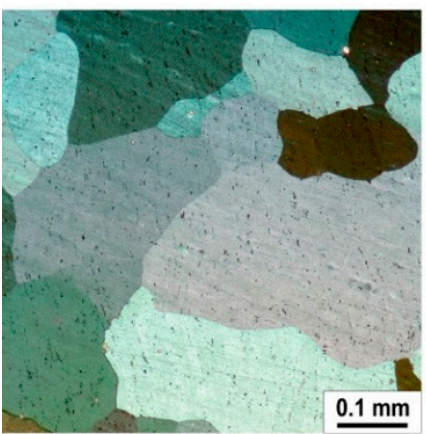

$\varphi=0.35 ; d=143.6 \mu \mathrm{m}$

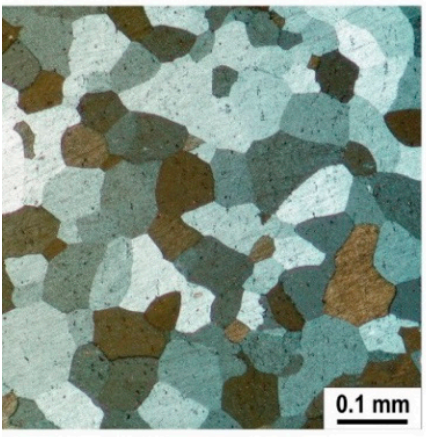

$\varphi=0.8 ; d=58.6 \mu \mathrm{m}$

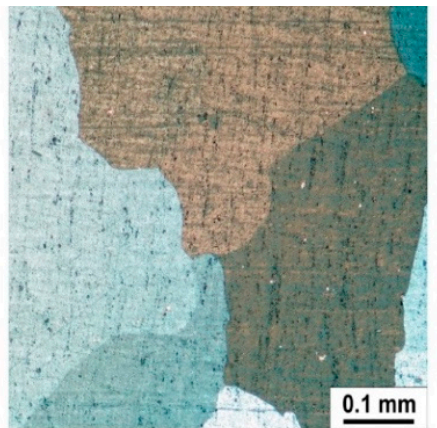

$\varphi=0.16 ; d=376.5 \mu \mathrm{m}$

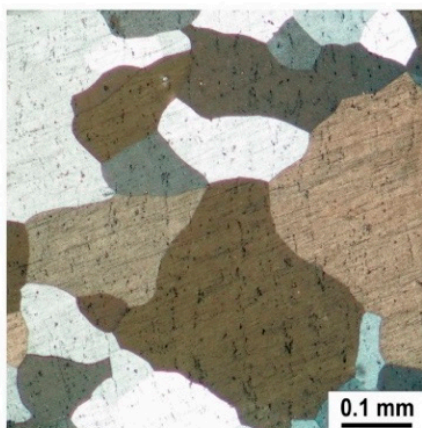

$\varphi=0.45 ; d=104.2 \mu \mathrm{m}$

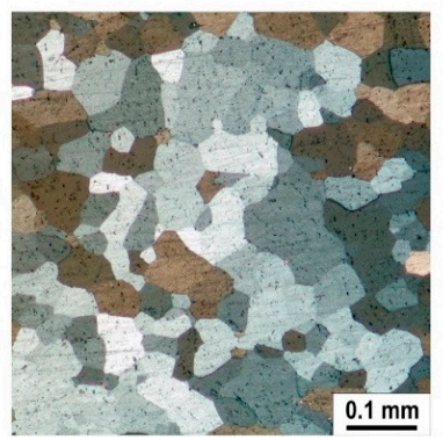

$\varphi=0.97 ; d=56.0 \mu \mathrm{m}$

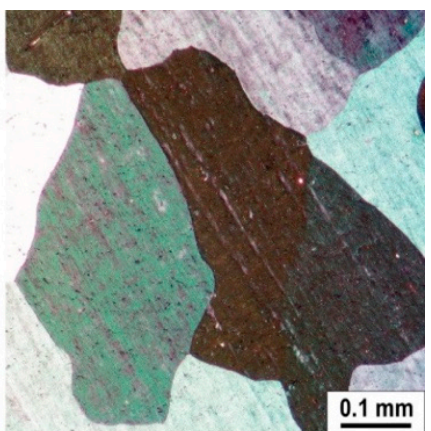

$\varphi=0.28 ; d=203.3 \mu \mathrm{m}$

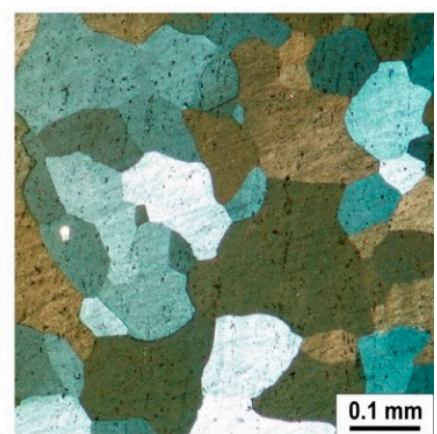

$\varphi=0.61 ; d=66.2 \mu \mathrm{m}$

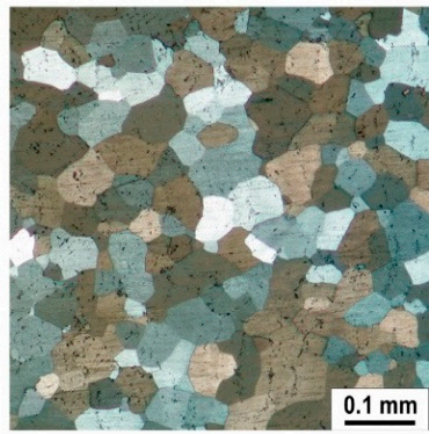

$\varphi=1.07 ; \mathrm{d}=53.1 \mu \mathrm{m}$

Figure 6. Grain size microstructure for different strains $\varphi$ (polarized LM). 


\subsection{Macro and Micro-Structure, and Microhardness of the Gear-Like Element}

The macrostructure of one-third of the representative section is presented in Figure 7. From this macro presentation, it can be seen that grain size and their distribution are ununified. Although the heat-treated microstructure before deformation was quite uniform in grain size, from Figure 7 it can be seen that the grain size is now totally different, as a result of different strain values obtained during the extrusion process. It is easy to observe the areas (zones) of different grain sizes. The large grains are in the middle of the tooth and between teeth, very small grains are in the root of the tooth and at the surface, and the semicircle (circlet) zone of small grains is between each tooth root.

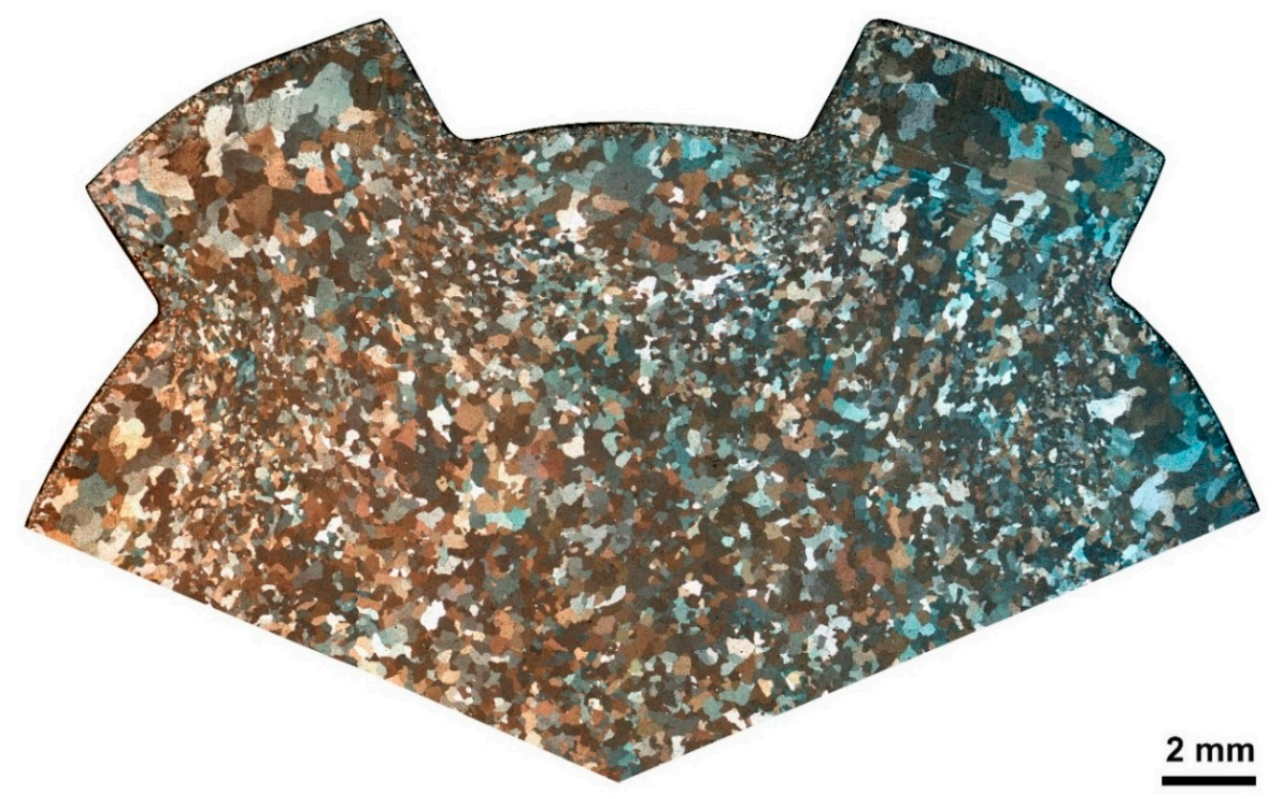

Figure 7. Macrostructure of one-third of the gear-like element (polarized LM).

The results of the grain size and microhardness measurements for the $30^{\circ}$ segment of the gear-like element are presented graphically in Figures 8 and 9, respectively (black dots represent the position of measurement in polar coordinates). The positions of measurement were chosen according to the observed difference in microstructure (grain size difference), with more measurements in zones of fine grains, and less in zones of uniform larger grains (greater distance between positions of measurement). The subsequent color plots (Figures $8 \mathrm{~b}$ and 9) were represented by the graphing software OriginPro8.6 (OriginLab Co., Northampton, MA, USA) with graph mode Polar Contour Plot.

From Figure 8 it is easy to observe, previously noticed, different zones of grain size, as grain diameter has a great spread between minimum and maximum values. The grain diameter varies from 51 to $399 \mu \mathrm{m}$. On the other hand, although microhardness results correspond to grain size (small grain - high hardness, and vice versa), the zones are not so easily observed as repeatability in hardness measurement is lower, and the difference between $\mathrm{min} / \mathrm{max}$ values is reduced, Figure 9.

The illustration of grain appearance in different zones (Figure 8a) obtained from the $30^{\circ}$ segment of the gear-like element is presented in Figure 10 (the midpoint of Figure $10 \mathrm{a}-\mathrm{h}$ is approximately indicated by arrows in Figure 8a). The highest grain size was in the middle of the tooth (zone 5a) and in the zone between the teeth (zone 5b), close to the surface. On the other hand, the smallest grains were obtained at the root of the tooth and at the surface of the element (zone 1 to 4 ). Furthermore, between each tooth root (zone 3) was a zone with grains from very fine (zone 3) to fine (zone 6) in the middle between tooth roots. This "circlet" was surrounded by large grains between teeth close to the surface (zone 5b) and medium-size grains in the intermediate zone between the surface and the center (zone 7). In the center of the cylindrical part of the element (zone 8), grain size values were slightly lower than in the intermediate zone (zone 7). 

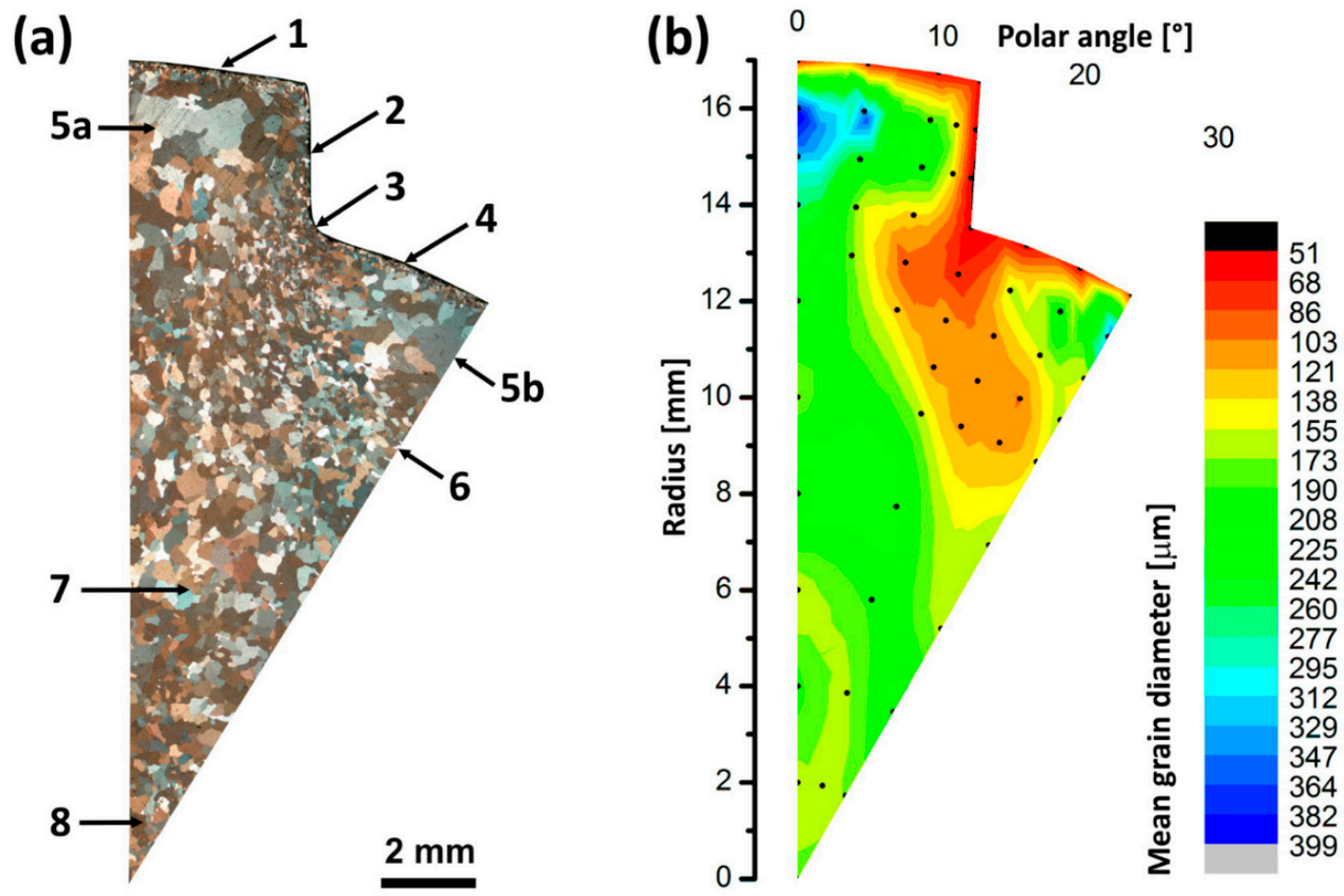

Figure 8. Grain size in the $30^{\circ}$ segment of the gear-like element: (a) grain size zones (the midpoint of the zone is approximately indicated by arrows; polarized LM); (b) distribution of the mean grain diameter (black dots represent the position of measurement in polar coordinates; OriginPro8.6, Polar Contour Plot).

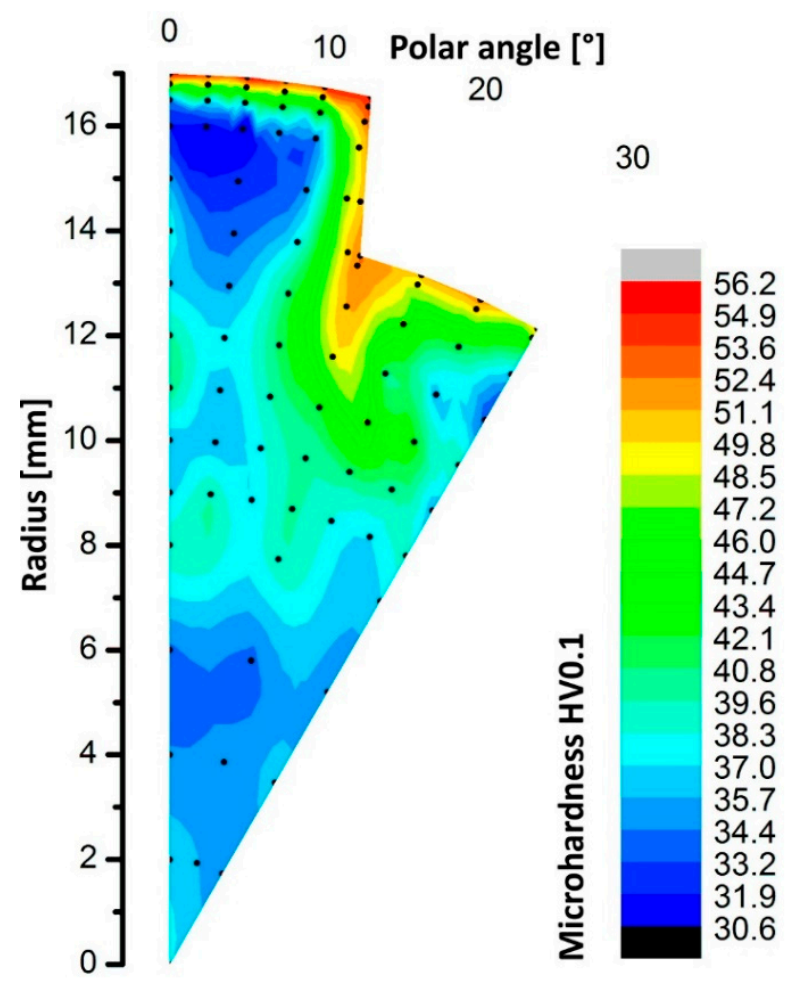

Figure 9. Distribution of the microhardness in the $30^{\circ}$ segment of the gear-like element (black dots represent the position of measurement in polar coordinates; OriginPro8.6, Polar Contour Plot). 

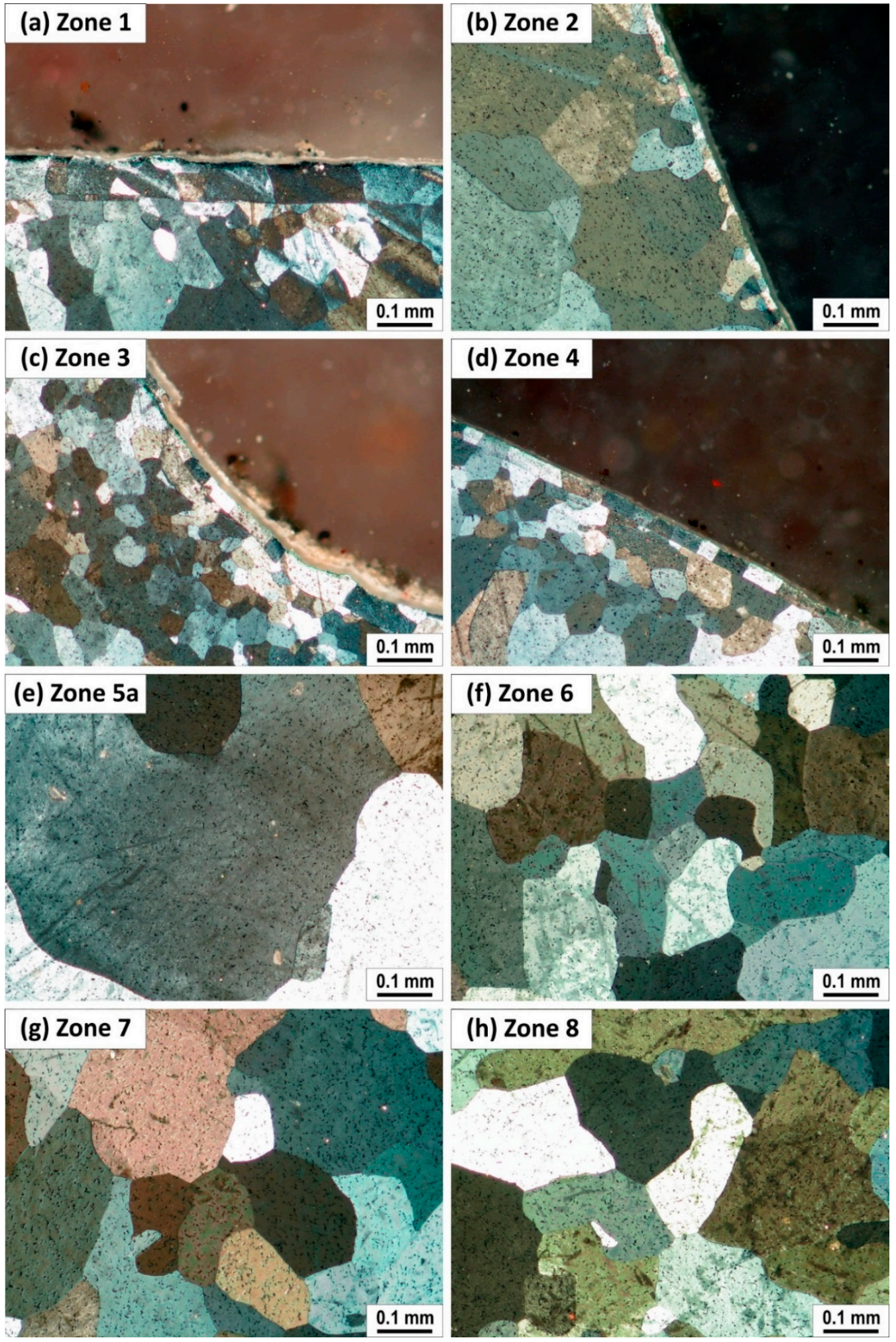

Figure 10. Grain size zones in the $30^{\circ}$ segment of the gear-like element (polarized LM; the midpoint of Figure 10a-h is approximately indicated by arrows in Figure 8a): (a) zone 1 (top side of the tooth), $\mathrm{d}=63 \mu \mathrm{m}$; (b) zone 2 (the side of the tooth); $d=52 \mu \mathrm{m}$; (c) zone 3 (the root of the tooth), $d=55 \mu \mathrm{m}$; (d) zone 4 (the surface between the teeth), $d=59 \mu \mathrm{m}$; (e) zone 5a (the center of the tooth), $d=399 \mu \mathrm{m}$; (f) zone 6 (the middle between tooth roots), $\mathrm{d}=152 \mu \mathrm{m}$; (g) zone 7 (the intermediate zone between surface and center), $d=227 \mu \mathrm{m}$; $(\mathbf{h})$ zone 8 (the center of the gear-like element), $d=173 \mu \mathrm{m}$. 


\subsection{Strain and Stress Distribution}

The strain and the stress states are also graphically presented in Figure 11. It should be noted that the strain values in the section (Figure 11a) were determined using grain size from Figure $8 \mathrm{~b}$ and the calibration curve (Figure 6), i.e., by using the curve fitting equation (Equation (2)). The stress state represented by Figure $11 \mathrm{~b}$ was obtained using the strain state and the flow curve equation (Equation (1)).
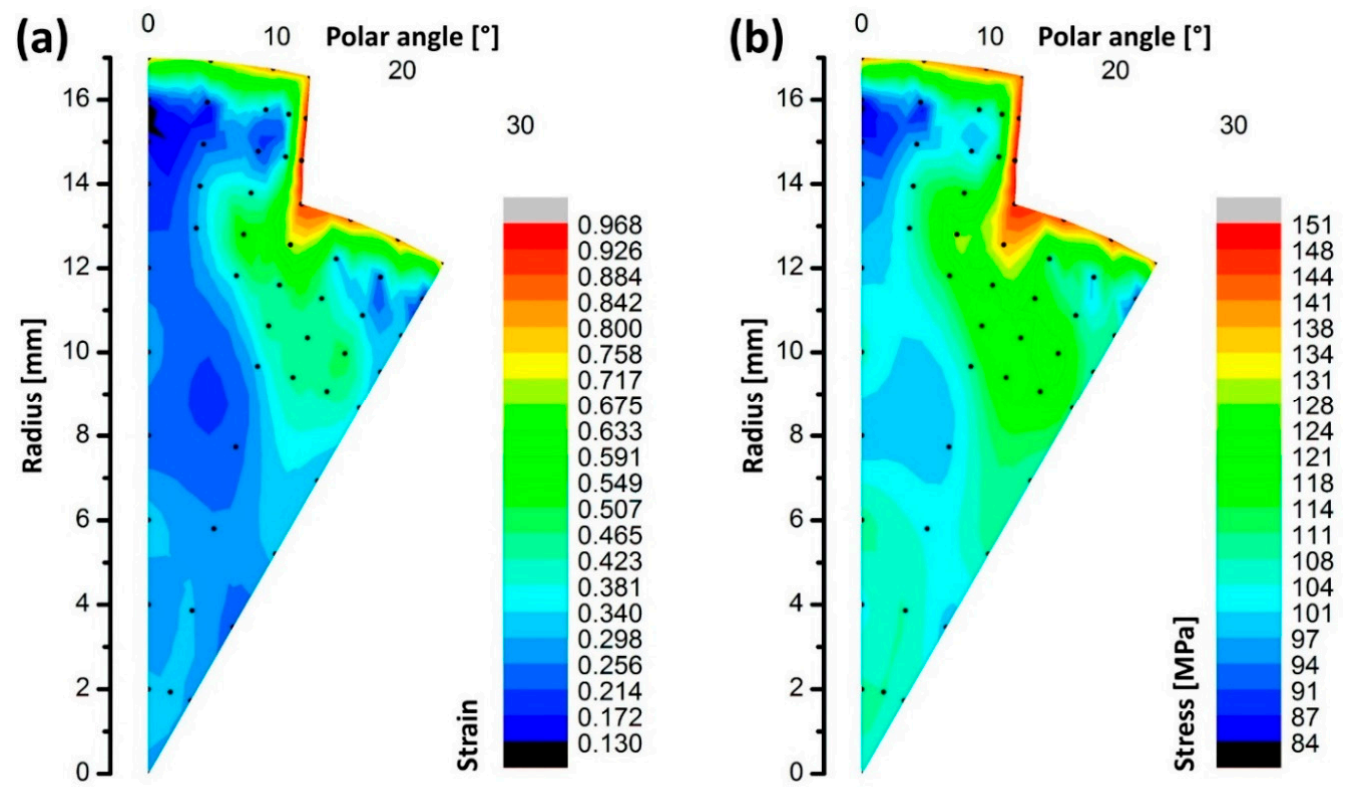

Figure 11. Strain (a) and stress (b) state in the $30^{\circ}$ segment of the gear-like element (black dots represent the position of strain/stress calculation based on grain size measurements from Figure 8b; OriginPro8.6, Polar Contour Plot).

\section{Discussion}

At the beginning of the extrusion process, when the billet is pressed by the punch, the easiest way for material to flow is toward die cavities where teeth are formed. Thus, the highest values of the grain size are in the middle of the tooth, together with the lowest values of strain. That means that material is only slightly deformed, and that is almost translated to the die cavity. Another zone where relatively low deformation is observed is the area between the teeth, close to the surface. However, in this zone, there was no significant flow of the material to free surfaces of die, but deformation is achieved mostly by punch upsetting.

In the center part of the gear-like element, the intermediate values of strain were observed. In addition, the strain values were not homogenous. Slightly higher values were in the very center than in the rest of it. These results could be explained by the fact that in that zone, the material was predominantly upset and stress values are higher than in the rest of the center volume, where material can flow toward die cavities, which caused the stress to decrease.

The highest strain values were obtained at the tooth root and at the surface of the gear-like element. The tooth root was the zone of the highest concentration of stress, as caused by a high change in the direction of material flow. As material between teeth does not flow significantly, because that requires a great change of material flow direction, deformation and flow of material to the tooth is done by high deformation of the material in the "circlet" zone (see Figure 7). The "circlet" zone represents a zone of intensive deformation caused by the flow of material to the tooth and the pressure of material flow from the center of the part.

The highest strain is obtained at the surface of the gear-like element as a result of the friction influence and high pressure in the extrusion process, especially at the final stage. Thus, the finest grains in those thin surface zones appear. 
Similar results are presented in Reference [1] where strain distribution obtained by numerical simulation in the cold rotary forging process is presented. It can be seen from the results of the simulation that the largest values of the effective strain are located in the area of the tooth root of the forged spur bevel gear, but those results showed only strain values on the surface, without any presentation inside of the part. Further results only for the surface strain distribution are presented in the Reference [2], which consider lateral extrusion of the gear-like part, while strain distribution attained also by numerical simulation within a part volume is presented in Reference [12]. The effective strain value of the addendum (top) is lower than that of the dedendum (root), which indicates that the metal of this area undergoes the highest degree of deformation.

The experimental technique utilized for estimating the effective strain distribution based on micro-hardness measurements is presented in Reference [14]. The relationship between microhardness and the effective strain was determined by the microhardness measurement of several specimens with known values of effective strain. Experimental results were compared with numerical simulation. Both results showed that the highest values of strains were found at the outside contact surface between the workpiece and the tool.

Those results are in accordance with results obtained in this paper by the metallographic method, as the highest deformation was detected in the tooth root, as well as at the surface of the gear-like element. Comparing the metallographic method and simulations, it could be said that the metallographic method gave more accurate information on zone distribution, especially in this case, regarding surface deformation zone depth. Furthermore, the microhardness measurement, used in Reference [14], as well in this paper shows that deformation zones could be determined, but with lower precision, as the microhardness measurement was more dependent on the place of indentation (smaller grains, larger grains, grains boundary, distance from free surface etc.), while the metallographic method gave the mean grain diameter in the field of view and also gave direct visualization of the deformation zones (see Figure 7).

Finally, it could be summarized that through the introduced metallographic method, the real view of material flow in the extruded part was successfully obtained.

\section{Conclusions}

In this paper, the metallographic method for strain distribution within plastically deformed parts using grain size is presented.

The results obtained show that the application of this method enables very reliable information of metal flow during the forming process of aluminum gear-like components. This is especially important for complex shape parts manufacturing because zones of critical strain values can be seen clearly.

It can be also concluded that the finest grains, as well as the highest strain and stress, were found in the surface part of the gear-like element, practically in the root of the teeth. On the other hand, the largest grains, and thus the lowest values of strain and stress, were in the middle of the teeth, indicating that material from the surface flowed to the die cavity with low deformation. The highest flow of material was in the "circlet" zone.

By strain hardening of the gear-like element surface, and especially of the teeth roots during cold extrusion, a more failure resistant gear was obtained. This clearly indicates that one of the major advantages of cold extrusion over machining is the increased mechanical properties.

Author Contributions: Conceptualization, P.S. and L.S.; formal analysis, P.S., D.R., S.B., A.S. and P.N.; investigation, P.S, D.R., P.J.; methodology, P.S., D.R. and L.S.; validation, A.S. and P.N.; resources, S.B.; data curation, P.S., D.R. and P.J.; writing-original draft preparation, P.S., D.R., P.J., S.B., A.S., and P.N.; writing-review and editing, P.S., D.R. and L.S.; visualization, D.R. and P.J.; supervision, L.S. All authors have read and agreed to the published version of the manuscript.

Funding: This research received no external funding.

Conflicts of Interest: The authors declare no conflict of interest. The funders had no role in the design of the study; in the collection, analyses, or interpretation of data; in the writing of the manuscript, or in the decision to publish the results. 


\section{References}

1. Xiaobin, D.; Lin, H.; Xinghui, H.; Yanli, S. Numerical and experimental investigation of cold rotary forging of a 20CrMnTi alloy spur bevel gear. Mater. Des. 2011, 32, 1376-1389. [CrossRef]

2. Jafarzadeh, H.; Faraji, G.; Dizaji, A.F. Analysis of lateral extrusion of gear-like form parts. J. Mech. Sci. Technol. 2012, 26, 3243-3252. [CrossRef]

3. Politis, D.J.; Lin, J.; Dean, T.A.; Balint, D.S. An investigation into the forging of Bi-metal gears. J. Mater. Process. Technol. 2014, 214, 2248-2260. [CrossRef]

4. Choi, J.; Cho, H.; Choi, J. Upper bound analysis for forging of trochoidal gears. J. Mater. Process. Technol. 2000, 103, 347-352. [CrossRef]

5. Chitkara, N.R.; Bhutta, M.A. Shape heading of splines and solid spur gear forms: An analysis and some experiments. Int. J. Mech. Sci. 2001, 43, 1073-1106. [CrossRef]

6. Can, Y.; Misirli, C. Analysis of spur gear forms with tapered tooth profile. Mater. Des. 2008, $29,829-838$. [CrossRef]

7. Song, J.H.; Im, Y.T. The applicability of process design system for forward extrusion of spur gears. J. Mater. Process. Technol. 2007, 184, 411-419. [CrossRef]

8. Sidor, J.J.; Petrov, R.H.; Xie, Q.; Van Houtte, P.; Kestens, L.A.I. Evaluation of crystallographic changes and plastic strain ratio in Al alloys. Mater. Sci. Technol. 2017, 33, 667-677. [CrossRef]

9. Nouri, M.; Mohammadian, S.H.; Emadoddin, E.; Seop, K.H. Investigation of direct extrusion channel effects on twist extrusion using experimental and finite element analysis. Measurement 2018, 127, 115-123. [CrossRef]

10. Kim, J.H.; Lee, M.G.; Kang, J.H.; Oh, C.S.; Barlat, F. Crystal plasticity finite element analysis of ferritic stainless steel for sheet formability prediction. Int. J. Plast. 2017, 93, 26-45. [CrossRef]

11. Feng, W.; Hua, L.; Han, X.H. Finite element analysis and simulation for cold precision forging of a helical gear. J. Cent. South Univ. 2012, 19, 3369-3377. [CrossRef]

12. Zeramdini, B.; Robert, C.; Germain, G.; Pottier, T. Numerical simulation of metal forming processes with 3D adaptive Remeshing strategy based on a posteriori error estimation. Int. J. Mater. Form. 2019, 12, 411-428. [CrossRef]

13. Faregh, S.S.H.; Hassani, A. Stress and strain distribution in twist extrusion of AA6063 aluminum alloy. Int. J. Mater. Form. 2018, 11, 175-184. [CrossRef]

14. Alves, M.L.; Rodrigues, J.M.C.; Martins, P.A.F. Cold forging of gears: Experimental and theoretical investigation. Finite Elem. Anal. Des. 2001, 37, 549-558. [CrossRef]

15. Oyekanmi, B.O.; Hughes, T.A.; Bramley, A.N. A microstructural evaluation technique for deformation studies in metal forming processes. J. Mater. Process. Technol. 1990, 21, 75-89. [CrossRef]

16. Ha, J.; Lee, J.; Kim, J.H.; Lee, M.G.; Barlat, F. Investigation of plastic strain rate under strain path changes in dual-phase steel using microstructure-based modeling. Int. J. Plast. 2017, 93, 89-111. [CrossRef]

17. Vilotic, D.; Alexandrov, S.; Plancak, M.; Movrin, D.; Ivanisevic, A.; Vilotic, M. Material formability at upsetting by V-shape dies. Steel Res. 2011, 2011, 923-928.

18. Jawale, K.; Duarte, J.F.; Reis, A.; Silva, M.B. Characterizing fracture forming limit and shear fracture forming limit for sheet metals. J. Mater. Process. Technol. 2018, 255, 886-897. [CrossRef]

19. Qi, Y.; Kosinova, A.; Lakin, E.; Popov, V.V., Jr.; Rabkin, E.; Lapovok, R. Effect of SPD Processing on the Strength and Conductivity of AA6061 Alloy. Adv. Eng. Mater. 2019, 21, 1801370. [CrossRef]

20. Larianovsky, N.; Popov, V.; Katz-Demyanetz, A.; Fleisher, A.; Meyers, D.E.; Chaudhuri, R.S. Production of Al Metal Matrix Composites Reinforced With Carbon Nanotubes by Two-Stage Melt-Based HPDC-CE Method. ASME. J. Eng. Mater. Technol. 2019, 141, 011002. [CrossRef]

21. International Cold Forging Group. 40 Years History Document; Document No18/07; ICFG: Los Angeles, CA, USA, 2007.

(C) 2020 by the authors. Licensee MDPI, Basel, Switzerland. This article is an open access article distributed under the terms and conditions of the Creative Commons Attribution (CC BY) license (http://creativecommons.org/licenses/by/4.0/). 